\title{
田
}

\section{RESOLUCIONES DEL G2O EN LOS CABOS, MÉXICO}

\author{
G20 resolutions in Los Cabos, México
}

\section{Julio C. Gambina'}

La principal decisión asumida en Los Cabos, México por el cónclave de los presidentes del G20 es la capitalización del Fondo Monetario Internacional (FMI) por 456.000 millones de dólares.

Como parte de ese monto, la zona del euro le aportará al organismo 200.000 millones, de los cuales, los españoles se comprometieron con 18.800 millones. Es sabido que Europa y el euro estuvieron en el centro de los debates, por la crisis y el ajuste que ella supone. Así y todo, los gobernantes de la eurozona transferirán nada menos que 200 mil millones de dólares al FMI, para prestarle a los "países en problemas". Suena increíble pero es verdad.

La crisis se manifiesta en crecimiento del desempleo, la marginación, el empobrecimiento, y dificultades de la población de menores ingresos; y la solución es acrecentar la capacidad de préstamos del FMI. Si hay un organismo responsable de la crisis en curso es precisamente el FMI.

Sorprende que países como Brasil e India, con inmensos bolsones de pobreza y atraso, cada uno aportará 10.000 millones de la moneda estadounidense al Fondo; igual que Rusia con una cifra similar. China, otro que concentra inmensa población empobrecida contribuirá con 43.000 millones; y Sudáfrica con 2.000 millones. Imagine-

\footnotetext{
${ }^{1}$ Doctor en Ciencias Sociales de la UBA. Profesor de Economía Política en la U.N. de Rosario. Profesor de posgrado en Universidades de Nuestramérica. Presidente de la FISYP. Integrante del Comité Directivo de CLACSO.E-mail: <jcgambina@ gmail.com>.
} 
mos esos fondos aplicados a políticas alternativas en beneficio de los más necesitados entre los pueblos de esos mismos países.

Todos ellos son los países BRICS (Brasil, Rusia, India, China y Sudáfrica), los emergentes que están de moda; los que se supone disputan la hegemonía mundial desde su lugar ascendente en la economía; que obviamente incluye el financiamiento de la crisis.

Alguna vez mencionamos que la categoría emergente supone una calificación funcional a las necesidades de inversión del capital global. Se es emergente ante la vista del inversor que busca niveles adecuados de rentabilidad. En la crisis emergen ciertos países, donde conviene invertir.

Son emergentes para los inversores. No es una calificación que destaca virtudes sobre las condiciones de vida de la población, sino que apuntan a virtudes requeridas por los capitales en búsqueda de ganancias, precisamente en momentos de crisis, donde el eje es la dificultad para valorizar a los capitales.

Otros emergentes también aportan, tal el caso de Corea del Sur, que aportará 15.000 millones de dólares; México lo hará con 10.000 millones; Turquía con 5.000 millones; y Colombia con 1.500 millones.

Por su parte, Japón se anotó con 60.000 millones, y EEUU se abstuvo de aportar en la ocasión, en un claro acto de transferencia de los costos de la crisis mundial al resto del mundo.

El G20 recapitaliza al FMI, tal como ya hizo en ocasiones anteriores, ahora con 456.000 millones de dólares. ¿Para qué? Para prestarle a los países endeudados (países con problemas), para que puedan cancelar sus deudas con los bancos y aportar al salvataje del sistema bancario en crisis.

La voz de los 20, más allá de altisonantes declaraciones a favor del "[... ] crecimiento y del empleo [...]", volvieron a salvar a los bancos en problemas, y lo hicieron con recursos públicos.

El Estado salió nuevamente a resolver los problemas del capitalismo en crisis. ¿No era que había que evitar la participación del Estado en la Economía? ¿Dónde quedó el credo liberal, o neoliberal? ¿Son todos keynesianos? Keynes era un neoclásico, que pensó en la 
renovación del pensamiento hegemónico ante la crisis para salvar al capitalismo en la década del 30 del Siglo XX; que ahora se manifiesta como un modo de pensar pragmático en la coyuntura de la recidiva crisis del capitalismo.

\section{TODAS LAS FICHAS AL CRECIMIENTO}

Lo que hay que salvar es el funcionamiento del capitalismo, y por eso las llamadas a la salida de la recesión o desaceleración económica.El G20 se pronuncia por aplicar "[... ] políticas de crecimiento [...]", como si cualquier crecimiento fuera bueno en sí mismo.

Es algo a interrogar a los ambientalistas reunidos en Río de Janeiro a propósito de la contaminación de la cidade maravilhosa, con la Bahía de Guanabara poluída (altamente contaminada), situación similar a lo que ocurre en las grandes ciudades de nuestramérica (de la crónica de María Elena Saludas, participante de la cumbre popular en Río+20).

Vale la crónica ya que una de las propuestas del G20 se concentra en la inversión para infraestructura, que suena muy bien a los oídos "[... keynesianos, desarrollistas, o neo desarrollistas [...]", que asocian inversión con crecimientoy bienestar.

Así se justifica la inversión en infraestructura para saquear las riquezas naturales de nuestramérica, para lo que vale recordar la vieja conquista, y por qué no, la nueva aventura por la mega minería a cielo abierto, o la sojización de los países del Mercosur, proceso que entre otras cuestiones, desestabiliza al presidente paraguayo, tal como denuncia Idilio Méndez en su artículo: Monsanto golpea en Paraguay: los muertos de Curuguaty y el juicio político a Lugo.

Es Monsanto la misma empresa que enorgulleció a la presidente de la Argentina en la reciente reunión en Nueva York con los empresarios estadounidenses, donde se conocieron las inversiones de la transnacional por 150 millones de dólares en las provincias de Córdoba y Tucumán.

¿Estamos contra el crecimiento y las inversiones? No. El problema es que no se trata de cualquier crecimiento, ni de cualquier inver- 
sión. Si la inversión capitalista se define por la obtención de ganancia del inversor, resulta conveniente discutir bajo qué circunstancias se define la inversión capitalista, especialmente cuando se alude al capital global.

El G20 apunta a la búsqueda de nuevas fuentes de rentabilidad del capital, y no necesariamente a satisfacer necesidades de la población.

En los medios de comunicación y en la sociedad se instaló un debate donde los buenos son los que recomiendan políticas de crecimiento, entre los que estaría EEUU (Obama necesita un repunte económico para ganar un segundo periodo en las próximas elecciones de renovación presidencial en noviembre) y los países emergentes (recordar el significado de emergente); y los malos los que sostienen políticas de austeridad y ajuste, especialmente Europa, y más precisamente Alemania.

Entre los primeros están los críticos de las políticas neoliberales, aunque no tengan reparos a la hora de otorgarle 456.000 millones de dólares al FMI para facilitar créditos condicionados a los países en problemas. Son condicionamientos que incluyen la campaña electoral, como en Grecia, donde el FMI chantajeó para que la Izquierda Radical no triunfara en las elecciones recientes, claro que fue una gestión en la que estuvo acompañado por el Banco Central Europeo y las autoridades de la Eurozona.

No hay buenos y malos en la consideración de la crisis; solo matices sobre como resolver la crisis capitalista, y por eso el crecimiento, para restablecer el consumo, sí, pero especialmente la valorización, esencia del desarrollo de la sociedad capitalista. Es necesario que aparezca una voz diferenciada, con críticas al capitalismo en crisis, y que proponga superar, no solo la crisis, sino el capitalismo.

\section{RESTAURAR LA CONFIANZA}

Junto al crecimiento buscado, se puede leer en las Declaraciones finales del G20 que superar la recesión y desaceleración, restablecerá la confianza.

Es bueno interrogarse ¿confianza en que qué, para qué, en quiénes? 
Entre las medidas sustentadas en la Declaración del G20 se puede leer el estímulo a la búsqueda de acuerdos para una unión bancaria en Europa, para "[...] examinar medidas concretas en vista a una arquitectura financiera más integrada, que incluya la supervisión, la reestructuración y la recapitalización bancarias, así como el aseguramiento de los depósitos [...]", todo a junto a promover "[... ] empleo de calidad [... ]". Confianza en el sistema bancario.

El discurso de la regulación bancaria y la arquitectura financiera está dicho luego del salvataje de la banca española por 100.000 millones de euros; de la estafa de banqueros y ejecutivos de cuantiosos ingresos pese a la crisis, al desempleo y a la miseria. Claro, todo para salvaguardar el sistema, los depósitos y los "empleos de calidad".

Resulta poco creíble pensar en las resoluciones del G20 como “[... ] medidas necesarias para reforzar el crecimiento mundial y restaurar la confianza [...]", como si en ello fuera el buen vivir de la población vulnerable. ¿Cuántos recursos públicos han sido ya canalizados al salvataje de bancos y empresas quebradas?

Parte de la búsqueda de la confianza se concentra en el llamado a una tregua en las acciones proteccionistas sobre el comercio mundial, por lo menos hasta el 2014. Es el eufemismo para instalar el discurso hegemónico del capital transnacional por la liberalización de la economía mundial.

Es el programa de la OMC, de los Organismos financieros internacionales, y el legado principal de lo que se llamó el Consenso de Washington: la promoción del libre comercio, del libre cambio, de la apertura de los mercados para la penetración de los capitales más concentrados.

Cada G20 termina siempre con evocación al programa de máxima: la liberalización de la economía mundial, base de sustentación del programa de salida de la crisis de los 70', y que en la región americana se manifestara a través del ALCA, y luego en los tratados regionales o bilaterales por el libre comercio. No en vano una de las noticias que presentó Obama a los anfitriones, fue la invitación a México para ser parte del Acuerdo de Asociación Transpacífica, una negociación comercial plurilateral que involucra además del país 
azteca, a Nueva Zelanda, Australia, Brunei, Malasia, Singapur, Viet Nam, Chile, Perú y EEUU.

Este es un proyecto que involucra a 500 millones de habitantes; un $26 \%$ del PBI mundial; un $15 \%$ de las exportaciones mundiales y un $18 \%$ de las importaciones globales. Es un acuerdo que EEUU utiliza para su proyección sobre el Pacífico en competencia con China.

La confianza buscada es para relanzar el proyecto capitalista y superar la crisis. En el próximo tramo brasileño de los debates, Río+20, se incorporarán los mensajes de un capitalismo verde, con empleos verdes. Es un mensaje que busca consenso social ante la conciencia ecologista vigente. Pero ese proyecto verde, de ensoñación de los ideólogos del capitalismo contemporáneo, se asocia a la explotación depredadora de los recursos naturales.

¡Ojo con la confianza a restaurar! La confianza puede hacernos cambiar nuestras riquezas naturales por espejitos de color, verde, por supuesto.

\section{LA PROPUESTA ES POR OTRO MODELO PRODUCTIVO Y DE DESARROLLO}

En variados debates me señalan mi pesimismo en las soluciones que se ensayan, incluso en gobiernos progresistas (que no dejan de ser capitalistas).

Son los mismos que me endilgan mi optimismo por la creciente indignación de un movimiento social que no tiene claridad sobre el rumbo a seguir, y solo se afirma en el $\mathrm{NO}$ a la realidad que les toca vivir, la del ajuste y la austeridad (Grecia, Italia, Europa en general, ahora, y de Nuestramérica en lasúltimas dos décadas del Siglo $X X)$.

No es menor afirmarse en el NO. A veces es un grito de dignidad, aunque no se conozcan los $\mathrm{SI}$, y que sin embargo se abren paso entre nuevos desafíos que instala el constitucionalismo renovado en Bolivia, Ecuador, o Venezuela; la propia renovación socialista en Cuba, e incluso las búsquedas de expresiones organizadas del movimiento popular por un movimiento de constituyentes sociales, que emergen en Argentina, Chile, Colombia, entre otras expe- 
riencias de organización popular en la construcción de un proyecto emancipador. En ese camino se inscribe la lucha por la soberanía alimentaria, energética, financiera, ambiental.

Los NO son el modelo productivo y de desarrollo capitalista contemporáneo, sustentado a la superexplotación de la fuerza de trabajo y la depredación de los recursos naturales. Los SI apuntan a nuevas formas de relación económica, social, política y cultural para reproducir la vida cotidiana en armonía con el conjunto social y los bienes comunes.

En definitiva, ni pesimismo, ni optimismo, sino reivindicación del NO y emergencia y difusión de nuevos SI. ¿Resulta simple? Claro que no. Es parte dela búsqueda por una nueva sociedad. El fantasma de los indignados recorre el planeta, y no se trata de jóvenes interconectados mediante nuevas tecnologías de comunicación y redes sociales, sino de trabajadores sin empleo, flexibilizados, precarizados, súper explotados, mayoritariamente jóvenes que rechazan el presente sin futuro y reescriben su propia historia emancipadora, liberadora.

Si el ciclo inaugurado por el Manifiesto hizo evidente el surgimiento de la práctica y teoría revolucionaria que inspiró históricas luchas de clases entre 1848 y la ruptura de la bipolaridad; el presente es un momento de imaginación creativa en la emergencia de renovadas perspectivas para la teoría y práctica de la revolución.

Buenos Aires, 20 de junio de 2012. 